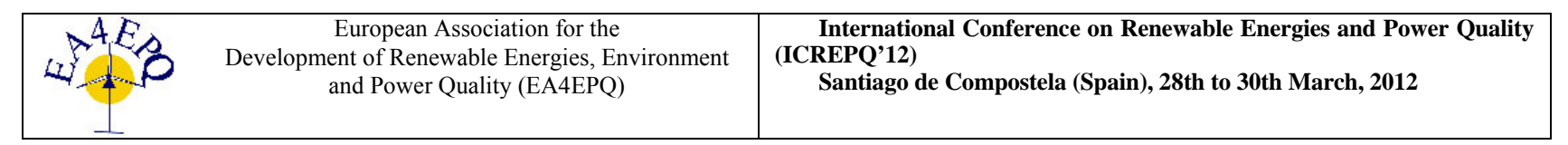

\title{
Design of a Solar Harvester System for a Wireless Sensor Network Deployed for Large Aircraft In-Flight Tests
}

\author{
D. Meekhun ${ }^{1,2}$, V Boitier ${ }^{1,2}$, J.M. Dilhac ${ }^{1,2}$ \\ 1 CNRS ; LAAS ; 7 avenue du Colonel Roche, F-31077 Toulouse, France \\ 2 Université de Toulouse ; UPS, INSA, INP, ISAE ; LAAS ; F-31077 Toulouse, France
}

\begin{abstract}
: this paper deals with the sizing of a few watts solar harvester. CIGS cells are used for the harvester and supercapacitors for the storage. The power management is explained. Practical results are exhibited. Small thickness (5mm) and large temperature range $\left(-50^{\circ} \mathrm{C}+100^{\circ} \mathrm{C}\right)$ are the main requirements.
\end{abstract}

Keywords : wireless sensors network, aircraft, photovoltaic, harvester, supercapacitor, MPPT, buck converter.

\section{Introduction}

Flight tests of a commercial aircraft consist of gathering data during flight to validate aircraft design. With respect to new aircrafts, it deals with the comprehensive development and certification of the aircraft series. Flight tests are very expensive for various reasons. One of them is that most of the sensors implemented to collect data are wired. As an example, an Airbus A380 incorporates 300 miles of cables and wirings, to which 180 miles have to be added for inflight tests [1]. A wireless solution is, therefore, of great interest; however, such a cable-less implementation implies both wireless transmission of data together with energy autonomy

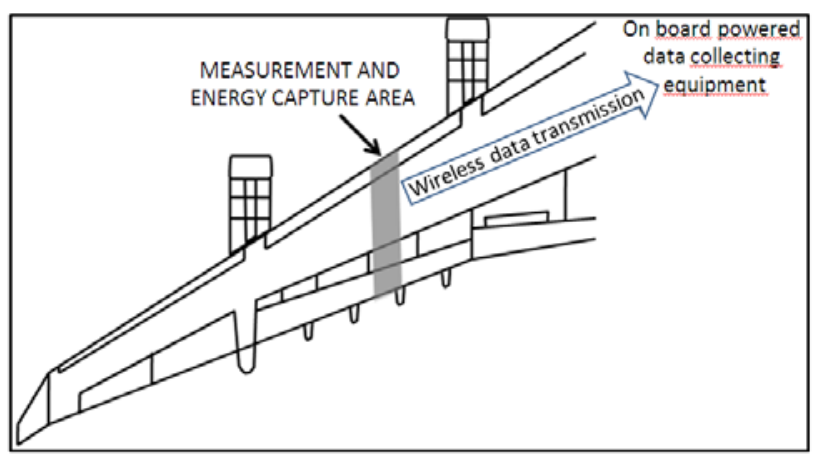

Figure. 1 Schematic of the sensor network topology

The purpose of this paper is therefore to describe a strategy for power generation and management for a wireless sensor network (WSN) implemented for in-flight tests dealing with aerodynamic pressure measurement on the outside of the aircraft wings (see Fig.1).

The main requirements are therefore related to the thickness of the system (less than $5 \mathrm{~mm}$ in order not to disturb the aerodynamic air flow) and the output power (3W per sensor node in order to power the sensor, data processing and transmission system). In addition, the system has to properly work at extremely high and low temperature $\left(-50\right.$ to $\left.100^{\circ} \mathrm{C}\right)$.

\section{Related Work and Background}

One drawback to moving towards a wireless network installation is the need to supply electrical power to the sensor, radio, processor, and other electronic elements of the system. However several energy harvesting systems for wireless sensor networks have been proposed in [2-8]. The system presented in [2] has a solar panel and two secondary Nickel Metal Hydride batteries. The solar panel is directly connected to the batteries through a diode. The advantage of this system is its simplicity. In [3], the system uses a secondary Li-Polymer battery to store energy. The system is designed to maximize the utility of ambient power from a sensor system with multiple ambient power sources, leading to lower power draw from the battery. However, the main disadvantage of the systems is that the systems lifetime is limited to the batteries' lifetime. One solution that slows down battery aging is to place a supercapacitor in parallel with the battery so that transient power is delivered by the supercapacitor rather than the battery. This method is proposed in [4-6]. In [4, 5], the systems have a solar panel for energy harvesting. However the lack of maximum power point tracking (MPPT) substantially limits the harvesting efficiency of these systems. The system presented in [6] utilizes multiple energy harvesting sources. It is implemented entirely with analog circuitry. This system performs MPPT by using a sensor that tracks the supply condition. The system presented in [7] has a solar panel and a supercapacitor. It does not have a battery; however it has an MPPT circuit. This system is complex, but the novelty lies in the feed forward pulse frequency modulated converter and open-circuit solar voltage method for MPPT.

Unfortunately the systems presented above operate only at room temperature. In [8], a power management system for thermal energy harvesting in aircrafts is presented. It is focused on thermoelectric devices, where a large energy potential is available from the temperature difference between the cabin and the aircraft body shell at high 
altitudes. Nevertheless, a design of a power generation system, focusing on photovoltaics, together with the associated management strategies for a wireless sensor network deployed for large aircraft in-flight tests and aeronautical application has never been published, to the authors' knowledge.

\section{System Global Architecture}

Aeronautical applications out of the cabin may require operation at temperatures as low as $-50{ }^{\circ} \mathrm{C}$. However, an aircraft operates not only at low temperature but may also be parked in direct sunlight producing high temperatures. The key design challenge is that the system should work properly in the overall temperature range $\left(-50^{\circ} \mathrm{C}\right.$ to $\left.100^{\circ} \mathrm{C}\right)$. Our system consists of three primary components to consider: the Energy harvesting system, the Energy storage device and the Energy management system.

The power of an energy harvester depends on the environmental conditions. For example the power of a photovoltaic cell varies with changes in solar radiation. Such an environmental energy capture will be considered in section $A$. In this section, we also summarize the comparison of the performance of different photovoltaic technologies at different temperatures concerning their availability and achievable power density in aircraft applications. In section $B$ we will investigate the possibility of using batteries and supercapacitors as a storage device. Finally, in section $C$, we encompass the implementation requirements for an actual in-flight test of the environmental energy management system.

\section{A. Energy Harvesting System}

The main objective of this section is to demonstrate the feasibility of a self-powered WSN. Power generation through harvesting and scavenging energy from the environment is contemplated.

Considering the potential energy sources within the studied context, a tentative list is as follows: solar energy, variations of atmospheric pressure during flight, thermal gradients, aircraft structure mechanical vibrations, acoustic noise, etc. However, since the tests are often be organized in sunlight, and the sensing will be performed on the extrados of the wing (upper surface see Fig.1) solar energy is the choice of interest because - compared to other sources - it delivers the highest power density per unit area. Additionally various commercial products are available in packages compatible with our application. This section investigates photovoltaic current versus voltage (I-V) measurement performed on indoor quartz halogen light source [9]. The tests are performed under climate chamber to evaluate temperature on maximum photovoltaic power. The tests are realized under different temperature and irradiation conditions that are not available in theirs datasheet view.
A comprehensive system for measurement of the I-V characteristics of solar cells is presented in [10]. Three different technologies of commercial photovoltaic cells were tested: Amorphous Silicon Photovoltaic Cells [11], CIGS Thin Film Photovoltaic Cells [12] and Multi junction Photovoltaic Cells (Triple junction) [13]. In spite of better performances, triple junction cells, too fragile, were not selected. The two other technologies are on a flexible support, but as expected, the photovoltaic efficiency of the amorphous silicon is very low comparing with others photovoltaic technologies and thus, the CIGS thin film photovoltaic cell is chosen for our application.

The photovoltaic efficiency $\left(\eta_{P V}\right)$ is the proportion of sunlight power that the solar cell converts to electrical power. It is defined by the equation (1).

$$
\eta_{P V(G, T)}=\frac{P_{M P}}{G \cdot S}
$$

where $P_{M P}$ is the maximum power delivered by the solar cell (W), $G$ is the input light irradiance $\left(\mathrm{W} / \mathrm{m}^{2}\right)$ and $S$ is the solar cell surface area $\left(\mathrm{m}^{2}\right)$.

Experimental measures of $\eta_{P V}$ realized in indoor or outdoor conditions are exhibited in Fig. 2.

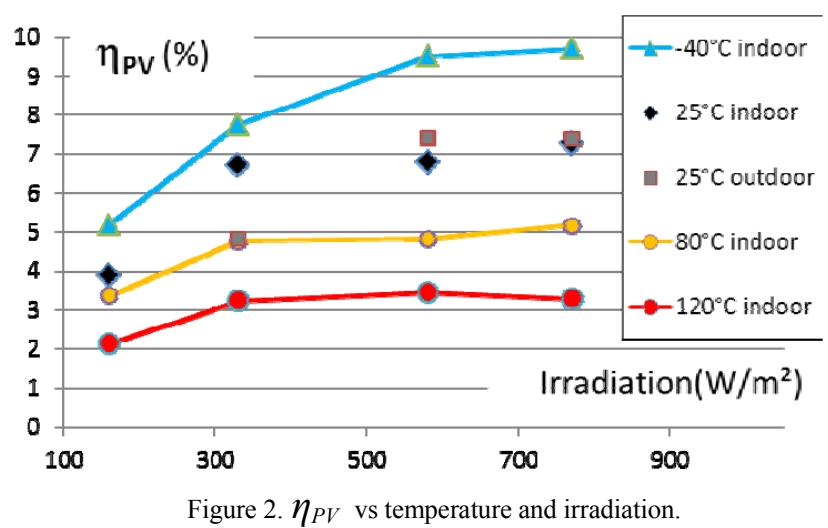

The consumption of the WSN is 3 Watts. Taking account a global efficiency of the conversion chain of $70 \%$ and including $0.2 \mathrm{~W}$ for charging rapidly the supercapacitors, the photovoltaic generated power $\mathrm{P}_{\mathrm{D}}$ must be equal or superior to $4.5 \mathrm{~W}$.

Hence, starting from $\mathrm{P}_{\mathrm{D}}$, we can derive, from the equation (1) and the fig. 2 the required surface area $S$ under various temperature and irradiation conditions. Typical and worst configurations are presented in Tab 1.

\begin{tabular}{|c|c|c|c|c|}
\hline conditions & $\begin{array}{c}\text { Temperature } \\
\left({ }^{\circ} \mathrm{C}\right)\end{array}$ & $\begin{array}{c}\text { Irradiation } \\
\left(\mathrm{W} / \mathrm{m}^{2}\right)\end{array}$ & $\begin{array}{c}\text { Estimated PV } \\
\text { Efficiency }(\%)\end{array}$ & $\begin{array}{c}\text { Calculated } \\
\text { Surface }\left(\mathrm{cm}^{2}\right)\end{array}$ \\
\hline worst case & 25 & 200 & 3 & 7500 \\
\hline typical & 120 & 800 & 3 & 1875 \\
\hline Tab 1. Expected surface to generate $4.5 \mathrm{~W}$ under various conditions.
\end{tabular}


In conclusion, the CIGS thin film photovoltaic cells have been chosen for our application with a surface area of $650 \mathrm{~cm}^{2}$ (active surface area of the Sunlinq2 module $\left.[14], \mathrm{V}_{\mathrm{OC}}=15 \mathrm{~V}, \mathrm{I}_{\mathrm{SC}}=0.27 \mathrm{~A}\right)$ in order to generate $4.5 \mathrm{~W}$ under sufficient conditions.

\section{B. Energy Storage Device}

Generally speaking, energy storage is an essential part of power generation for a wireless sensor network, to accommodate for transient lost of the environmental energy source or peak power demand from the load. As energy storage devices two different concepts are suitable: rechargeable batteries and supercapacitors [15].

In [16] and [17], we present experiment results aimed at analyzing commercial Li-Polymer and Ni-MH batteries' performances at extreme temperatures $\left(-40,+80^{\circ} \mathrm{C}\right)$. They show that the tested batteries are capable of supplying energy for a period of time at both extremely high and low temperature. However with poor performance compared to $25^{\circ} \mathrm{C}$ in term of capacity and lifetime.

Consequently, we intend to use super capacitors for our application. This paper presents the evolutions of the supercapacitors characteristics operating under an extended temperature range. The tests are carried out on the $\mathrm{PC}-10$ from Maxwell with 10F that has a low-self discharge [8]. Our proposed experiment uses an Autolab electrochemical instrument, PGSTAT 30, in order to obtain a constant charge and discharge current of the supercapacitor. Figure 3 presents PC10 supercapacitor charge and discharge characteristics at different temperatures.

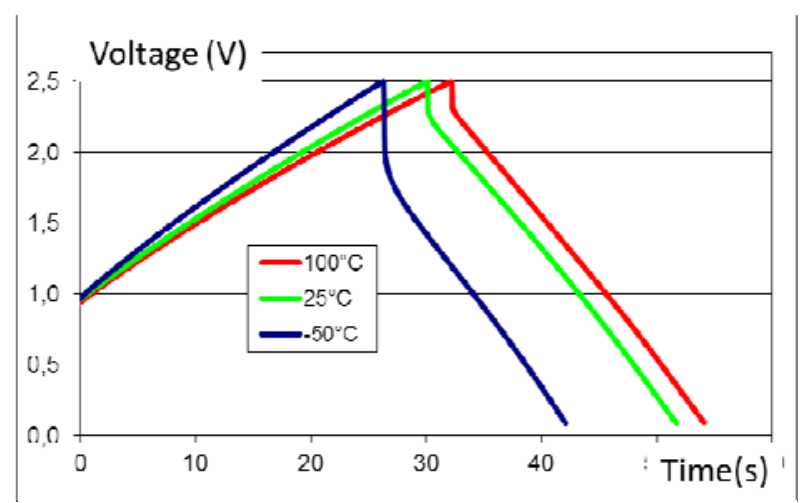

Figure 3. Charge @,500 mA. and discharge curve @,900 mA. of a PC10 supercapacitor under different temperatures.

A supercapacitor's voltage depends on the capacitance C (F) of the electrochemical double layer of the material and its Equivalent Series Resistance noted R $(\Omega)$. The ESR comprises the electrolyte resistance, the current collectors' resistance, the electrode resistance and the transfer resistance. The evolution of the change of the resistive and capacitive contributions at different temperatures is presented in Fig.4. Its resistive and capacitive values are extracted from experimental results (Fig.3) using the simplest RC model, which has only a series RC branch.
The results show that the PC10 supercapacitor performance depends on operating temperature and its performance at extremely low temperatures is significantly decreased compare to $25^{\circ} \mathrm{C}$. In fact, Fig. 4 shows that the capacitive component of the supercapacitor significantly reduces and the resistive component increases as temperature goes down.

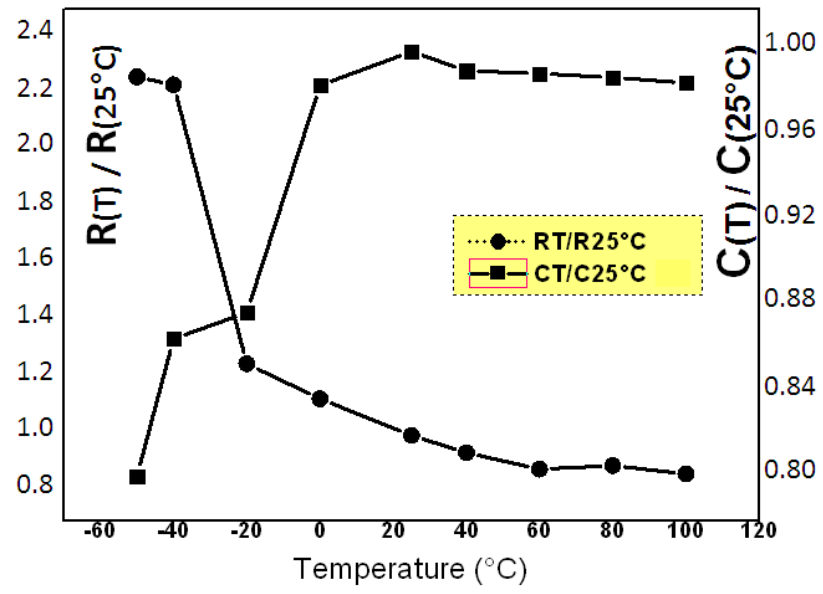

Figure 4. Influence of the temperature on the resistive and capacitive realtive values.

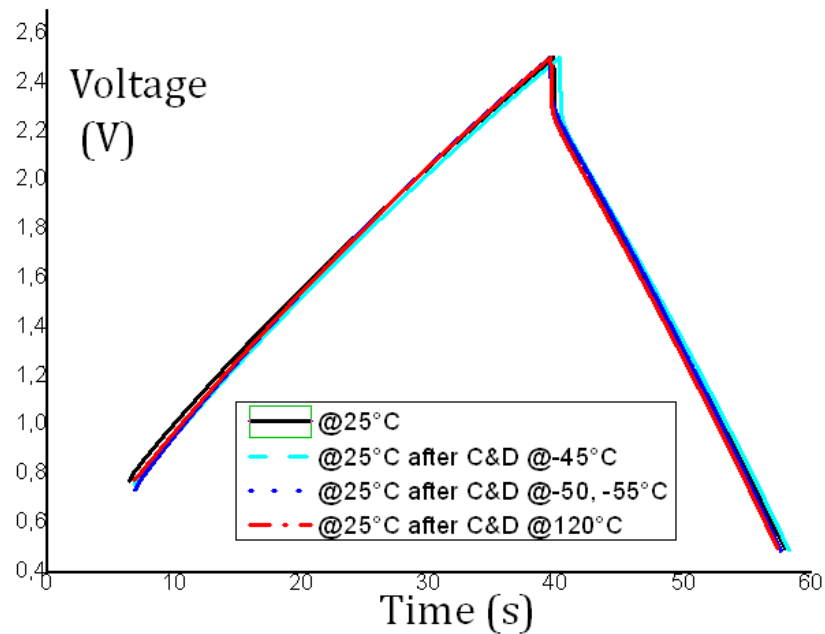

Fig. 5 Charge @ $500 \mathrm{~mA}$. and discharge curve @ $900 \mathrm{~mA}$ of the PC10 supercapacitor at $25^{\circ} \mathrm{C}(\mathrm{C}=$ charge and $\mathrm{D}=$ discharge $)$

In addition, another experiment was run in order to assess the temperature effect on the lifetime of supercapacitor. A supercapacitor submitted to a charge and discharge cycle at an experimental temperature was retested at room temperature in order to study the temperature effect on the supercapacitor lifetime. Results are presented in Fig.5. We notice that the extreme temperatures don't have a direct impact on the cycle life of the supercapacitor. Because of this advantage, the PC10 supercapacitor is used for our application. Furthermore, after simulation of the discharge behaviour of $\mathrm{PC} 10$ supercapacitor at $-50{ }^{\circ} \mathrm{C}$ by Simulink ${ }^{\circledR}$, we determined that 5 sets of PC 10 mounted in parallel, with each set consisting of 2 serially mounted PC 
10 can approximately deliver a constant power of 3 watt for 50 seconds which the supercapacitors voltage varies from 5 to 3 volts.

\section{Energy Management System}

Energy harvesting sources depend on the power available from the environment. If the power disappears, for example during a transient loss of the environmental energy source, the sensor node should be powered by the supercapacitors. For this reason, the power management is essential. Generally, the power management has to convert the energy generated into an energy form that can be stored in the supercapacitors. This energy has to be converted again into the output power needed by the sensor node [8]. Figure 5 presents the electronic schematic of the energy management system. Our proposed energy management system is self-powered by solar panels. We describe the principle of each subsystem below. Note that to perform measurements in this section; a PV array simulator, E4360A of Agilent technologies, is used to generate DC power with the I-V curve characteristic of a CIGS PV array $\left(\mathrm{V}_{\mathrm{OC}}=15 \mathrm{~V}, \quad \mathrm{I}_{\mathrm{SC}}=0.27 \mathrm{~A}, \quad \mathrm{~V}_{\mathrm{MP}}=12.2 \mathrm{~V}, \quad \mathrm{I}_{\mathrm{MP}}=0.25 \mathrm{~A} \quad\right.$ in STC).

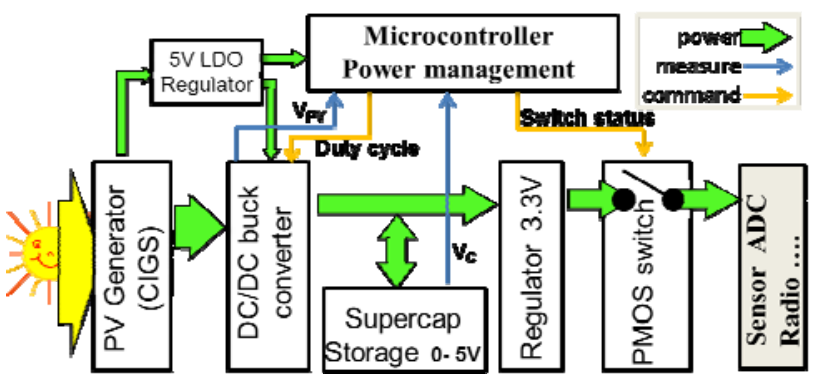

Figure 5. Electronic schematic of the energy management system

-BUCK converter: Our proposed converter is a synchronous Buck converter designed to process power from 1 to 7 watts. Its sizing has been presented in [18]. A Schottky diode is also connected in series on output of the BUCK converter in order to avoid reverse current from the supercapacitors.

-LDO voltage regulator: The electronic components, such as the microcontroller and the MOSFET driver in BUCK converter, require a $5 \mathrm{~V}$ supply to operate. It is furnished by solar panels energy through a 5 volt LDO voltage regulator TPS71550 (Vout $=5 \mathrm{~V}, 6 \mathrm{~V} \leq \mathrm{Vin} \leq 24 \mathrm{~V})$. Consequently, if the photovoltaic voltage falls under $6 \mathrm{~V}$, the power harvester is cut off and in this case, the load is only powered by supercapacitors.

-Algorithm implementation: To move the photovoltaic panel operating voltage close to the maximal power voltage $\mathrm{V}_{\mathrm{MP}}\left(\mathrm{P}_{\mathrm{PV}}=\mathrm{P}_{\mathrm{MAX}} @ \mathrm{~V}_{\mathrm{PV}}=\mathrm{V}_{\mathrm{MP}}\right)$, under various atmospheric conditions, a MPPT algorithm is implemented in a PIC18F1220 microcontroller. We considered two different
MPPT techniques: Hill-climbing and Fractional OpenCircuit Voltage Method $\left(\mathrm{V}_{\mathrm{MP}} \approx \mathrm{kV}_{\mathrm{OC}}\right)$. An experiment comparing global efficiency (product of the efficiency of a MPPT and the DC/DC converter conversion efficiency) under various conditions was implemented. The result shows that the total efficiency is about $70 \%$ with both methods. Finally, as only one sensor is required, the Fractional Open-Circuit Voltage Method is chosen for our application. The open circuit voltage of photovoltaic cell $\left(\mathrm{V}_{\mathrm{OC}}\right)$ is measured every 10 seconds by an interrupt function which calculate the new optimal voltage, the duty cycle is then adapted accordingly in the main program. When the supercapacitors' terminal voltage reachs almost its maximum voltage, the algorithm will move from MPPT mode to supercapacitors' voltage regulation mode.

-Buck-Boost regulator and PMOS: The output voltage from the BUCK circuitry varies with the supercapacitors' voltage $\left(\mathrm{V}_{\mathrm{C}}\right)$ from 0 to 5 volts. However the load requires a constant voltage. So, a Buck-Boost regulator (TPS63001) is placed between the supercapacitors and the load in order to fix the output voltage to 3.3 volts. The input voltage range of this component is $1.8 \mathrm{~V}-5.5 \mathrm{~V}$. Two TPS63001 are connected together in parallel. This improves the global efficiency of this stage to $85-88 \%$. For a 3 watts consumption under $3.3 \mathrm{~V}$, each regulator supplies $0.45 \mathrm{~A}$. We employed a PMOS switch between the TPS63001 regulators and the load. From a structural point of view, the PMOS should be placed between the capacitor set and the regulators in order to disconnect them when $\mathrm{V}_{\mathrm{C}}$ falls down under $1.8 \mathrm{~V}$. But at this location, the microcontroller can control the PMOS without any driver and in term of energy consumption, the result is the same.

This will allow the solar panel to firstly charge the supercapacitors. When the supercapacitors' terminal voltage reaches 3 volts, the PMOS switching is turned on by a microcontroller command. Then the solar panel will both power the load and charge the supercapacitors whenever the sun is shining strongly enough. If there isn't sufficient sunshine, the load will be only powered by the supercapacitors.

The power management board is exhibited on Fig. 7

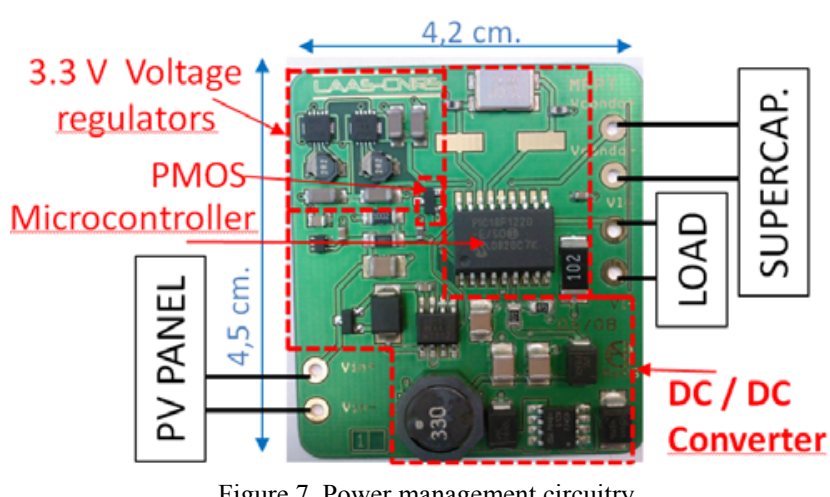

Figure 7. Power management circuitry. 
Final tests were realized with the power management board, a $25 \mathrm{~F} / 5 \mathrm{~V}$ capacitor made with a pack of 10 supercacitors PC10 (5 strings mounted in parallel, each string composed with 2 serially mounted PC 10), a potentiometric resistive load (fixed for 3W@3.3V) and for the photovoltaic generator, a Sunlinq2 CIGS module without its protection for outdoor tests and a PV simulator Agilent E4360A (parametrized for CIGS panel, $1300 \mathrm{~W} / \mathrm{m}^{2},-50^{\circ} \mathrm{C}$ : $\mathrm{P}_{\mathrm{MP}}=5.2 \mathrm{~W}$ ) for indoor tests.

\section{Results and Discussion}

In this section, we evaluate our complete system in terms of voltage and current levels and energy management system efficiency. Fig. 8 shows the experiment data collected under different conditions. We record the terminal voltage of the power source: solar panel simulator $\left(\mathrm{V}_{\mathrm{PV}}\right)$, the supercapacitors' terminal voltage $\left(\mathrm{V}_{\mathrm{C}}\right)$, and the voltage at load end of circuit $\left(\mathrm{V}_{\mathrm{LOAD}}\right)$. We also recorded the supercapacitors' current $\left(\mathrm{I}_{\mathrm{C}}\right)$ to see the supercapacitors charge and discharge characteristics. This test is performed at $25^{\circ} \mathrm{C}$.

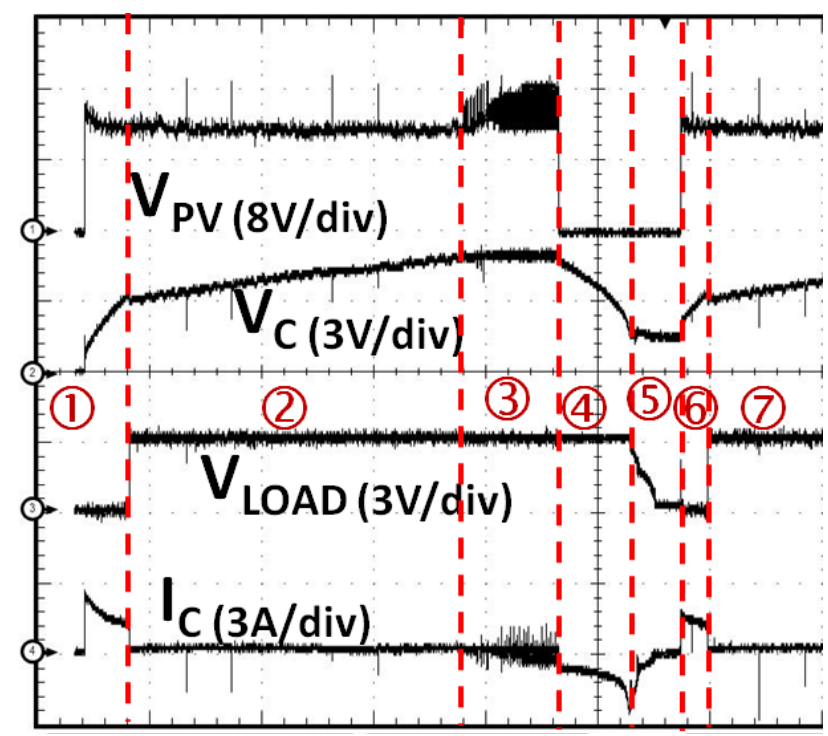

Figure 8. Voltages and current under various conditions.

Before the experiment starts, we completely discharge the supercapacitors. Advantageously, the system can autonomously start or restart even if the supercapacitors voltage is null as shown in figure 8 . Results are presented for different scenarios as described below:

1st scenario: PV simulator is connected at the start of the evaluation. PMOS switch is initially off. The photovoltaic panel operated close to its maximum power point. The supercapacitors are efficiently charged. 2nd scenario: When $\mathrm{V}_{\mathrm{C}}$, as detected by the microcontroller, reaches 3 volts the PMOS switch is commanded on. The load is powered and the supercapacitors are charging directly from photovoltaic panel.

3rd scenario: When $\mathrm{V}_{\mathrm{C}}$ reaches 4.8 volts, the solar panel supplies power directly to load. In this regulation mode $V_{C}$ remains between 4.8 to 5.0 volts.

4th scenario: If there is cloud cover (in our test, the PV simulator is disconnected), the supercapacitors assume the main role in powering the load. The supercapacitors can be used to power the load for approximately $50 \mathrm{sec}$. The LDO doesn't supply the microcontroller which is off.

5th scenario: When $\mathrm{V}_{\mathrm{C}}$ is lower than 2 volts. The $3.3 \mathrm{~V}$ regulators don't work properly so the load isn't powered.

6th scenario: When solar energy is available, the microcontroller starts up and first turns the PMOS switch off so the supercapacitors are first charged by solar panel until their voltage reaches 3 volts.

7th scenario: idem 2nd scenario.

Since the system presented in this work will be employed for aircraft applications, it should work properly at extremely low and high temperatures as well. To verify this, we performed multiple experiments to investigate the system performance over the temperature range from $-50^{\circ} \mathrm{C}$ to $100^{\circ} \mathrm{C}$. In table 3 , we present the total efficiency of the system for the 2nd, 3rd and 4th scenarios.

In the 2nd scenario, PV generator supplies both the supercapacitors and the load. The photovoltaic power $\mathrm{P}_{\mathrm{PV}}$ is closed to $\mathrm{P}_{\mathrm{MP}}$

$$
\eta_{2}=\frac{P_{\text {OUT }}+P_{C}}{P_{P V}}
$$

where $\mathrm{P}_{\text {OUT }}$ is the output power at load $(\mathrm{W})$ and $\mathrm{P}_{\mathrm{C}}$ is the power to charge the supercapacitors $(\mathrm{W})$

In the 3rd scenario, since the supercapacitors are fully charged the solar panels are only supplying power to the load.

$$
\eta_{3}=\frac{P_{O U T}}{P_{P V}}
$$

In the 4th scenario, the efficiency when the load is powered only by the supercapacitors is shown.

$$
\eta_{4}=\frac{P_{O U T}}{P_{C}}
$$


Finally, we present the duration that supercapacitors can power the load at 3 watts and 3.3 volts.

\begin{tabular}{|c|c|c|c|c|}
\hline Scenario $\rightarrow$ & $(2)$ & (3) & $(4)$ & \\
\hline Temperature $\downarrow$ & \multicolumn{3}{|c|}{ Efficiency (\%) } & Autonomy \\
\hline$-50^{\circ} \mathrm{C}$ & 70.1 & 71.2 & 88.3 & $52 \mathrm{~s}$ \\
\hline $25^{\circ} \mathrm{C}$ & 68.9 & 72.1 & 87.1 & $56 \mathrm{~s}$ \\
\hline $100^{\circ} \mathrm{C}$ & 69.7 & 71.9 & 85.5 & $53 \mathrm{~s}$ \\
\hline
\end{tabular}

Tab.3 Global system efficiency under different conditions

With the considered ultracapacitor pack, the autonomy with a consumption of 3 watts, in the absence of sunlight is approximately $55 \mathrm{~s}$. This duration can also be increased by connecting multiple supercapacitors in parallel and/or in series. Thereafter we observe the electricity consumption of the system including auto-discharge of the supercapacitors in the standby mode $\left(\mathrm{P}_{\text {OUT }}=0\right.$ watt $)$. The system gets no power from solar cells during this test. The result shows that the supercapacitors' terminal voltage approximately drops $0.67 \mathrm{mV}$ per second. It corresponds with $33 \mathrm{~mW}$. It means that the system will automatically turn off after 2 hours in stand-by mode.

\section{Conclusion}

We have reported the design details of a power generation and management strategy for a wireless sensor network deployed for large aircraft in-flight tests with an important permanent consumption of $3 \mathrm{~W}$. The purposed power management system for photovoltaic generators is capable of managing power to the load during transient loss of the environmental energy source over temperatures ranging from $-50^{\circ} \mathrm{C}$ to $100^{\circ} \mathrm{C}$. We have also demonstrated that the purposed structure is autonomous. In addition, the sensor nodes can operate for long life time because the solution does not rely on batteries.

\section{Acknowledgement}

This works has been supported by the Aerospace Valley World Competitiveness Cluster, "Aeronautics, Space and Embedded Systems"

\section{References}

[1]SAFRAN. Câblage aéronautique et engineering. [cited; Available from: http://www.safran-group.com/sitesafran/aeronautique/equipements-aeronautiques/cablageaeronautique-et/.

[2]Raghunathan, V., et al. Design considerations for solar energy harvesting wireless embedded systems in Proceedings of the 4th international symposium on Information processing in sensor networks 2005: IEEE.

[3] Park, C. and P.H. Chou. Power Utility Maximization for Multiple-Supply Systems by a Load-Matching Switch. in Proceedings of the 2004 International Symposium on Low Power Electronics and Design, 2004. ISLPED '04. . 2004: IEEE.

[4] Alberolal, J., et al. Solar Inexhaustible Power Source for Wireless Sensor Node. in Instrumentation and Measurement Technology Conference Proceedings, 2008. IMTC 2008. . 2008: IEEE.
[5] Jiang, X., J. Polastre, and D. Culler. Perpetual environmentally powered sensor networks. in Fourth International Symposium on Information Processing in Sensor Networks. 2005: IEEE.

[6] Park, C. and P.H. Chou. AmbiMax: Autonomous Energy Harvesting Platform for Multi-Supply Wireless Sensor Nodes. in Annual IEEE Communications Society on Sensor and Ad Hoc Communications and Networks, SECON '06. 2006: IEEE.

[7] Simjee, F. and P.H. Chou. Everlast: Long-life, Supercapacitoroperated Wireless Sensor Node. in Proceedings of the 2006 International Symposium on Low Power Electronics and Design, 2006. ISLPED'06. . 2006: IEEE.

[8] Becker, T., et al. Power Management for Thermal Energy Harvesting in Aircrafts. in Sensors, 2008 2008: IEEE.

[9] Philips. Ampoule halogène Philips - 50W / 12V - BRL G6.35 $3300^{\circ} \mathrm{K}-50 \mathrm{H}$. [cited; Available from: http://transitek.com/details produit.php?id produit $=8651$.

[10] Meekhun, D., et al. An Automated and Economic System for Measuring of the Current-Voltage Characteristics of Photovoltaic Cells and modules. in Sustainable Energy Technologies ICSET 2008. 2008. Singapore: IEEE.

[11] Flexcell. Solarcharger. [cited; Available from: http://www.flexcell.com/.

[12] Energy, G.S. Flex Solar portable Charger. [cited; Available from: http://www.globalsolar.com/products/flex/.

[13] Spectrolab. Ultra Triple Junction (UTJ) Solar Cells. [cited; Available from: http://www.spectrolab.com/prd/space/cellmain.asp.

[14] http://www.globalsolar.com/products/retail/sunlinq-2 [15] Pasquier, A.D., et al., A comparative study of Li-ion battery, supercapacitor and nonaqueous asymmetric hybrid devices for automotive applications. Journal of Power Sources, 2003. Vol.115: p. $171-178$

[16] Meekhun, D., V. Boitier, and J.-M. Dilhac. Charge and Discharge performance of Secondary Batteries according to Extreme Environment Temperatures. in 35th Annual Conference of the IEEE Industrial Electronics Society. 2009. Porto, Portugal: IEEE.

[17] Meekhun, D., V. Boitier, and J.-M. Dilhac. Study of the ambient temperature effect on the characteristics and the lifetime of Nickel-Metal Hydride secondary battery. in The 9th Annual Electrical Power and Energy Conference. 2009. Montreal, Canada: IEEE.

[18] Meekhun, D., "Buck converter design for Photovoltaic generators with supercapacitor energy storage" , Renewable Energy \& Power Quality Journal, Nº9, 2011, ISSN: 2172-038X 